\title{
CINEMA COMO ARTE OU ENTRETENIMENTO: UMA VISÃO DE SEUS REALIZADORES E A ESTRUTURA ORGANIZACIONAL DE SUAS PRODUTORAS.
}

\author{
Giordano Schmitz Toldo* \\ giordanostoldo@gmail.com \\ Fernando Dias Lopes \\ fernando.lopes@ufrgs.br \\ *Universidade Federal do Rio Grande do Sul
}

http://dx.doi.org/10.1590/1413.2311.176.60848

Recebido em 14/12/2015

Aprovado em 14/02/2017

Disponibilizado em 07/08/2017

Avaliado pelo sistema "double blind review"

Revista Eletrônica de Administração

Editoras-chefe: Andrea Oltramari e Maria Ceci Misoczky

ISSN 1413-2311 (versão "on line”)

Editada pela Escola de Administração da Universidade Federal do Rio Grande do Sul

Periodicidade: Quadrimestral

Sistema requerido: Adobe Acrobat Reader

\section{RESUMO}

Esse trabalho abrange uma visão crítica sobre cinema como peça artística ou mercadológica estabelecendo uma relação com as características estruturais das produtoras. A pesquisa objetiva entender as formas como as empresas de cinema do Rio Grande do Sul se estruturam procurando uma correspondência com o tipo de cinema produzido. Para caracterizar as estruturas organizacionais foram utilizadas as definições de Richard Hall e Henry Mintzberg, sobre tipos de estruturas. O arcabouço teórico para compreender a visão dos realizadores sobre cinema foi construído com base em autores como Ricciotto Canudo, Jaques Aumont, Jean-Claude Bernadet, entre outros. As empresas estudadas foram: Avante Filmes, Gus Gus Cinema, Millimetros, Otto Desenhos, Tokyo Filmes, Panda Filmes, Prana Filmes, TGD.

A partir de entrevistas realizadas com as produtoras, dois conceitos de Mintzberg (1994) foram determinantes para as definições de estrutura: a Adhocracia e a Burocracia Profissional. Como resultado, percebeu-se que as empresas Avante Filmes, Gus Gus Cinema, Millimetros, Tokyo Filmes e Prana Filmes se encaixaram na categoria adhocrática e foram elas que apresentaram uma inclinação para o cinema de arte, reflexivo e de maior preocupação estética. Na Burocracia Profissional, há as produtoras Otto Desenhos, Panda Filmes e TGD, cujas produções cinematográficas se relacionam com questões primordialmente mercadológicas. O reconhecimento das diferenças estruturais e ideológicas permite que se avance nas políticas de desenvolvimento do cinema no estado e no país. Desenvolvimento ainda enraizado em políticas públicas de incentivo, fomento e apoio que procura ser democrático na distribuição de seus prêmios. Novas medidas governamentais de apoio ao audiovisual já correlacionam a distribuição do incentivo conforme a visão sobre cinema dos realizadores. Questões estruturais também servem de critérios para a criação dos incentivos. Conhecendo as produtoras na maneira como elas se estruturam e como elas idealizam suas 
produções, torna-se mais do que uma questão acadêmica, alcança os ramos da economia e da política.

Palavras-Chave: Cinema. Arte. Entretenimento. Estrutura organizacional. Incentivos públicos.

\begin{abstract}
This work includes a critical view of cinema as artistic or marketing piece establishing a relationship with the structural characteristics of producers. The research aims to understand the ways in which film companies in Rio Grande do Sul are structured for a match with the type of film produced. To characterize the organizational structures were used definitions of Richard Hall and Henry Mintzberg on types of structures. The theoretical framework to understand the vision of the filmmakers on cinema was built on authors like Ricciotto Canudo, Jaques Aumont, Jean-Claude Bernadet, among others. The companies studied were: Avante Filmes, Gus Gus Cinema, Millimetros, Otto Desenhos, Tokyo Filmes, Panda Filmes, Prana Filmes, TGD.

From interviews with the producers, two concepts of Mintzberg (1994) were instrumental in the structure settings: a Adhocracy and Professional Bureaucracy. As a result, it was noticed that companies Avante Filmes, Gus Gus Cinema, Millimetros, Prana and Tokyo Filmes fell into place in adhocrática category and it was they who showed a penchant for art cinema, reflective and more aesthetic concern. In the Professional Bureaucracy, there producing Otto Desenhos, Panda Filmes and TGD, whose film productions relate to issues primarily marketing. The recognition of structural and ideological differences allows you to skip the cinema development policies in the state and country. Development still rooted in public policies to encourage, promote and support that seeks to be democratic in the distribution of prizes. New government measures to support the audiovisual already correlate the distribution of incentive consistent with the vision of cinema of the filmmakers. Structural issues also serve as criteria for the setting of the incentives. Know the producers, how they are structured and how they envision their production, it is more than an academic question, it reaches the branches of the economy and politics.
\end{abstract}

Keywords: Cinema. Entertainment. Organizational structure. Public incentives.

\title{
RESUMEN
}

Ese trabajo comprende una visión crítica sobre cine como una pieza artística o mercadológica estableciendo una relación con las características estructurales de las productoras. La pesquisa objetiva entender las formas como las empresas de cine en Rio Grande do Sul se estructuran buscando una correspondencia con el tipo de cine producido. Para caracterizar las estructuras organizativas fueran utilizadas las definiciones de Richard Hall y Henry Mintzberg, sobre tipos de estructuras. El conjunto teórico para comprender la visión de los realizadores sobre cine fue construido con base en autores como Ricciotto Canudo, Jaques Aumont, Jean-Claude Bernadet entre otros. Las empresas estudiadas fueran: Avante Filmes, Gus Gus Cinema, Millimetros, Otto Desenhos, Tokyo Filmes, Panda Filmes, Prana Filmes y TGD.

Dos conceptos de Mintzberg (1994) fueran determinantes para las definiciones de estructura: la Adhocracia y la Burocracia Profesional. Como resultado, se percibió que las empresas Avante Filmes, Gus Gus Cinema, Millimetros, Tokyo Filmes y Prana Filmes si adecuan en la categoría adhocrática y fueran ellas las cuales presentaran una inclinación para el cine de arte,

REAd | Porto Alegre - Edição 86 - No 2 - Maio / Agosto 2017 - p. 167 - 190 
reflexivo y de mayor preocupación estética. En la Burocracia Profesional, hay las productoras Desenhos, Panda Filmes y TGD, cuyas producciones cinematográficas se relacionan con cuestiones primordialmente mercadológicas. El reconocimiento de las diferencias estructurales y ideológicas permite que se avance en las políticas de desarrollo del cine en el estado y en el país. Desenvolvimiento aún enraizado en políticas públicas de incentivo, fomento y apoyo que busca ser democrático en la distribución de sus premios. Nuevas medidas gubernamentales de apoyo al audiovisual ya correlacionan la distribución del incentivo según la visión sobre cine de los realizadores. Cuestiones estructurales también sirven de criterios para la creación de los incentivos. Conocer las productoras, como ellas se estructuran y como ellas idealizan sus producciones, tornase más que una cuestión académica, alcanza los ramos de la economía y de la política.

Palabras Clave: Cine. Arte. Entretenimiento. Estructura organizativa. Incentivos públicos.

\section{INTRODUÇÃO}

As relações do público com o filme do qual acabou de assistir, e as discussões que são geradas pela obra, costumam ser sobre as qualidades estéticas, sobre a atuação dos atores, sobre a fotografia e sobre outras qualidades intrínsecas ao filme, mas raramente habitam o campo extra-filme. Quando isso ocorre, principalmente dentro da cinefilia, costuma-se debater sobre os profissionais do cinema como os diretores, os roteiristas, os fotógrafos, mas pouco se relaciona o filme com sua empresa produtora, como se não houvesse indícios, no fotograma, ou no cinema em que se assiste ao filme, sobre as características da empresa que produziu aquela determinada obra.

Esse estudo nos insere num campo mais amplo do mercado cinematográfico do Rio Grande do Sul e se preocupa em analisar as relações entre a estrutura organizacional das produtoras, conteúdo e percepção sobre a natureza dos filmes produzidos. A partir da coleta de dados, pode-se perceber um cinema possível desde o "Cinema de Um Homem Só", tese levantada pelo realizador Gustavo Spolidoro, que se desprende de conceitos mercadológicos e estruturais, até o realizado pelas produtoras com uma estrutura funcional clássica: divisões horizontais e verticais definidas; por fim, um ponto de equilíbrio com empresas em um nível estrutural mais simples, no qual o número reduzido de integrantes permite maior coesão no processo de tomada de decisões da empresa. Com peculiaridades significativas, cada produtora surge para suprir as demandas do mercado de cinema ou para sustentar as aspirações artísticas de produtores e diretores, que em consequência podem despertar o interesse de nichos específicos de mercado.

REAd | Porto Alegre - Edição 86 - № 2 - Maio / Agosto 2017 - p. 167 - 190 
Ao falarmos de cultura, no entanto, não podemos ser rasos na visão sobre demanda, pois o cinema é uma mercadoria abstrata (Bernadet, 1980). A que demanda se referem os filmes analisados: demandas artísticas, que objetivam a realização pessoal do autor, ou demandas mercadológicas que operam no princípio microeconômico da oferta e demanda? Dessa pergunta formulamos a base dessa pesquisa: Há correlação entre as diferentes visões de cinema que cada produtora tem sobre seu produto e sua estrutura organizacional? Nesse contexto, os filmes estariam divididos em sendo ou não sendo definidos como arte, cujo termo não tem vínculo com definições acadêmicas, mas sim com a visão de cada autor sobre seus filmes baseada nas suas referências e nas suas preferências estéticas.

Seja na qualidade técnica do filme, seja na sua forma de produção ou distribuição, a cadeia produtiva do Rio Grande do Sul se comporta de maneira heterogênea. As diferenças encontradas entre as empresas, que se originam em suas estruturas e nas formas como elas caracterizam seus próprios filmes, acabam determinando produtos de características e concepções singulares. Encontramos essas diferenças nas três principais etapas da realização de uma obra audiovisual: a pré-produção, a produção e a finalização, que podem ser resumidas respectivamente como períodos para revisão de roteiro, captação de recursos, formação de equipe e planejamento da logística; a filmagem propriamente dita; por fim, a montagem, edição de som e mixagem, produção de efeitos visuais.

Concepções diferentes sobre cinema, arte e indústria não são novidades, nem exclusividades do Rio Grande do Sul. A própria origem do cinema está vinculada a uma contingência mercadológica: Thomas Edison foi o primeiro a construir uma máquina capaz de registrar imagens sequenciais, o cinetógrafo, cuja filmagem podia ser vista através do cinescópio. Mas foram os Irmãos Lumière, em 1895, um ano após a invenção de Edison, que fizeram com que as imagens capturadas por uma câmera fossem projetadas numa sala de cinema, e para assistir foi preciso pagar ingresso. Dessa forma, a história clássica do cinema aponta a exibição de A chegada do trem, a primeira sessão paga, dos Irmãos Lumière, como o primeiro filme da história, e a data de 28 de dezembro de 1895 como o dia do nascimento do cinema. Embora reconheçamos a abordagem crítica da Escola de Frankfurt, principalmente a partir dos trabalhos de Adorno e Horkenheimer, da qual o cinema é defendido como mercadoria e como um produto da indústria cultural, entendemos que a própria dialética do mundo moderno tornou possível tanto a produção cinematográfica concebida como produto de puro entretenimento e alienação de massas (cinema Hollywoodiano), como um 
instrumento de produção de crítica social (por exemplo, o Cinema Novo no Brasil) e de espaço para o exercício da liberdade criativa.

A fim de compreender as diferentes estruturas das produtoras, foram revisados principalmente os estudos de Hall (1982) que, através dos conceitos de diferenciação, formalização e complexidade, tornaram possível classificar as variadas produtoras. Por conseguinte as empresas foram categorizadas a partir de seus designs estruturais baseados nos tipos de estruturas conceituados por Mintzberg (1994), que, no caso desse estudo, variam principalmente entre Adhocracia e a Burocracia Profissional, mas com uso significativo de mecanismos de coordenação típicos de estrutura simples.

\section{Revisão teórica}

1.1 O cinema como linguagem e estética (e indústria)

Como revisto por Brandão, o cinema definido como arte surgiu a partir de 1912 quando Rioccitto Canudo escreveu o artigo Manifesto das Sete Artes, designando o cinema como a sétima arte depois de arquitetura, escultura, pintura, música, dança e poesia.

Canudo inscreve o Cinema no domínio das outras Artes, conferindolhe um carácter estético; reconhece o Cinema enquanto linguagem, capaz de renovar, transformar e difundir as outras Artes, num projeto de Arte Total; paralelamente, o autor esforça-se por definir as propriedades do Cinema. (BRANDÃO, 2008, pg. 7)

A categorização de arte levou numerosos teóricos a discutirem a linguagem e a estética do cinema, propondo assim um conceito de arte.

\footnotetext{
A estética do cinema é, portanto, o estudo do cinema como arte, o estudo dos filmes como mensagens artísticas. Ela subentende uma concepção do "belo" e, portanto, do gosto e do prazer do espectador assim como do teórico. (AUMONT, 2011, pg.15)
}

Criaram-se Escolas e movimentos cinematográficos que objetivaram a exploração e a consolidação de paradigmas para a linguagem cinematográfica. Alguns movimentos e suas principais contribuições podem ser exemplificados como o Neorrealismo na Itália do pósguerra, que misturava cenas documentais com cenas interpretadas principalmente por atores não profissionais; o Cinema Novo no Brasil, e a ideia de um cinema que fizesse justiça à 
realidade pobre e de desenvolvimento do país, atribuindo ao cinema nacional um compromisso com a realidade que o país vivia.

\begin{abstract}
Enquanto a América Latina lamenta suas misérias gerais, o interlocutor estrangeiro cultiva o sabor dessa miséria, não como sintoma trágico, mas apenas como dado formal em seu campo de interesse. Nem o latino comunica sua verdadeira miséria ao homem civilizado nem o homem civilizado compreende verdadeiramente a miséria do latino. (ROCHA, 1965)
\end{abstract}

Serguei Einsenstein e Lev Kulechov são exemplos do grupo de teóricos do Formalismo Russo cujas contribuições, principalmente através das publicações na Poetika Kino, valorizavam a montagem como elemento principal da linguagem cinematográfica. Lev Kulechov ficou bastante conhecido pelo que se chama Experimento Kulechov, no qual o mesmo plano do rosto de um homem era intercalado com três planos distintos: o rosto de uma mulher, um prato de comida e uma criança morta. O resultado do experimento mostrou como um mesmo plano (o rosto do homem) pode estar servido de várias interpretações a partir dos planos que o sucedem, dando valor ao processo de montagem (XAVIER, 2008).

Comumente em paralelo aos grandes movimentos cinematográficos, a produção hollywoodiana buscou uma preocupação diferenciada na forma de ver cinema. Hollywood, que se construiu a partir de um cinema de estúdio e de uma ideologia industrial, via o cinema como uma grande forma de repercutir a ideologia norte americana de pensar, consumir e viver. Beto Rodrigues, da Panda filmes, acrescenta sobre o pensamento industrial do cinema hollywoodiano: "aonde vão nossos filmes, vão nossos produtos.". A preocupação sobre inovação estética dos filmes da indústria nos Estados Unidos pareceu não fazer parte das principais prioridades. O cinema de Hollywood, até meados da década de 50, era visto como um cinema do produtor, cujo cargo permitia tomar decisões sobre o filme, comumente em prol da aceitação comercial que a obra poderia ter. O produtor, a fim de obter o máximo do retorno financeiro que uma atriz ou um ator gerariam para o filme, poderia solicitar ao diretor que fizesse um close up para projetar nos cinemas a beleza do intérprete e buscar o sucesso de bilheteria.

Todavia, na história do cinema industrial, também houve espaço para diretores que reformularam a linguagem cinematográfica e propuseram novos paradigmas. Na era do cinema mudo, podemos citar D. W. Griffith que lançou, em 1915, O nascimento de uma nação, marcado pela polêmica sobre racismo. Vinte e seis anos depois, Orson Welles, já no 
cinema falado, lança Cidadão Kane, cujo estilo de filmagem inovador influenciaria uma gama de diretores. A percepção de que há nos filmes uma posição autoral do diretor foi um dos marcos de um dos últimos movimentos cinematográficos de grande escala, a Nouvelle Vague na França. Nomes como Jean-Luc Godard, François Truffaut, Alain Resnais, Jacques Rivette, Claude Chabrol, Eric Rohmer, Agnès Varda (pupilos em diferentes níveis de André Bazin) fizeram parte desse movimento que se caracterizou por exaltar a autoria do diretor na obra cinematográfica e trazer, ao cinema, temáticas jovens, heróis antiéticos e rompimentos com linguagem clássica. As críticas em que expressavam suas ideias eram publicadas na revista Cahiers du Cinéma. François Truffaut fora um dos responsáveis pela nova leitura dos filmes de Alfred Hitchcock, cujo domínio da linguagem cinematográfica do diretor americano passava muitas vezes despercebida dentro de um cinema industrial.

As ideias da Nouvelle Vague inovaram o cinema de Hollywood. Uma leva de diretores jovens, cuja formação vinha principalmente das novas escolas de cinema, chamou a atenção dos grandes estúdios. Martin Scorsese, George Lucas, Steven Spielberg, Stanley Kubrick, Woody Allen, entre outros, foram responsáveis por trazerem a Hollywood novas temáticas e novas proposições estéticas aos filmes.

A ambivalência do cinema de arte ou de indústria é uma questão cuja origem data o princípio da história do cinema e perpetua-se até hoje. Há inúmeros pontos de vista sobre os significados de cinema de arte e cinema industrial. Há inclusive o pensamento neutro, como o do ex-diretor da Ancine Gustavo Dahl (2012): "esta sua dupla natureza coloca um dilema que na realidade é falso. Não é OU, é E. Arte e indústria”. O princípio de que qualquer filme tem como objetivo ser visto por um público é verdadeiro, porém as diferentes linguagens propostas por diferentes autores precisam ser destacadas e pensadas de forma particular. Nichos criativos de cinema se formam com realizadores que dialogam entre si, mas que não partilham da mesma ideia de outros. É preciso lutar para que haja todo e qualquer tipo de produção cinematográfica nacional, entendendo quem são esses realizadores e como eles se articulam entre si, a fim de aperfeiçoar os incentivos públicos, sempre respeitando a visão de cada um sobre o cinema que faz.

\subsection{Estrutura Organizacional}

É através de sua estrutura que as relações dentro de uma organização se formam e permitem o desenvolvimento de habilidades individuais (Hatch, 1997). É no nível estrutural REAd | Porto Alegre - Edição 86 - No 2 - Maio / Agosto 2017 - p. 167 - 190 
que encontramos diferenças substanciais entre as organizações. Para compreender essas variações recorremos aos conceitos de Hall (1982) que nos revela três principais elementos estruturais: complexidade, formalização e centralização.

No início dos anos 1960, teóricos organizacionais perceberam que não era possível definir um modelo ótimo de complexidade, formalização e centralização; a cada organização cabia um modo de se estruturar que melhor condizia com sua cultura (Hatch, 1997). Muito antes disso, coube a Weber determinar estrutura como uma organização social onde há hierarquia de autoridade, divisão de trabalho e regras formais; em uma forma mais sintetizada, são a essas características que as definições de Hall se referem. Mintzberg (2009. p.12), por sua vez, define estrutura de uma organização como "a soma total das maneiras pelos quais o trabalho é dividido em tarefas distintas e, depois, como a coordenação é realizada entre as tarefas".

O artigo clássico de Ranson, Hinings e Greenwood (1980), adotando uma visão mais dinâmica de estrutura, aborda o problema de explanar como estruturas organizacionais mudam ao longo do tempo. Para isso, eles identificam o que é estrutura e desenvolvem um modelo teórico que explicará adequeadamente variações na estrutura organizacional. Os autores escrevem que o conceito de estrutura é usualmente entendido como uma configuração de atividades que é caracteristicamente estável e persistente, mantendo padrões de regularidade. Estruturas têm sido descritas como uma configuração formal de papeis, procedimentos, ou seja, um arcabouço prescrito da organização. Explicam também que outros autores tem descrito a estrutura como as regularidades padronizadas e processos de interação. Eles reconhecem essas distinções, mas chamam a atenção que a dicotomia entre padrões de interação e arcabouço prescrito são inadequados, ou seja, eles rejeitam a dicotomia agência/estrutura.

Partindo desse debate, Ranson, Hinings e Greenwood (1980) explicam que a produção e a recriação das formas estruturais através do tempo deveriam ser concebidas como resultado de uma complexa interação de processos interpessoais cognitivos, dependências de poder e constrangimentos ou limites contextuais. Extrapolando então as definições mais estáticas derivadas da abordagem contingencial, os autores enfatizam a maneira como as estruturas são continuamente produzidas e recriadas pelos membros de modo que as estruturas incorporam e se tornam constitutiva de suas províncias de significados. Para este trabalho, é importante a reflexão dos autores de que:

REAd | Porto Alegre - Edição 86 - No 2 - Maio / Agosto 2017 - p. 167 - 190 
As propriedades do arcabouço estrutural têm importantes consequências para a efetividade da organização: a extensão da diferenciação funcional, o grau de integração, conectividade e acoplamento, a centralização e concentração de autoridade, a formalização das regras e procedimentos, etc... irão influenciar a efetividade do controle, adaptabilidade e a motivação dos seus membros. Estrutura organizacional é, portanto, o arcabouço prescrito e as configurações realizadas de interações, bem como o grau para o qual elas são mutuamente constituídas e constituintes. (RASON, HININGS e GREENWOOD, 1980, p. 3)

Considerando os objetivos do trabalho, o foco no debate sobre estrutura será o arcabouço prescrito, já que a intenção não é entender a dinâmica das transformações estruturais, mas a relação entre padrões estruturais e o resultado ou natureza do trabalho da organização no que concerne ao seu conteúdo. Nesse sentido, justifica-se a opção pela abordagem revisionista de Hall (1982) e a abordagem contingencialista de estrutura de Mintzberg (1994).

Assim, retomando os elementos estruturais descritos por Hall (1982), pode-se explicar que a complexidade de uma organização é estudada a partir dos conceitos de diferenciação horizontal, diferenciação vertical e dispersão geográfica. O grau de complexidade pode variar em diferentes partes de uma organização, e a complexidade de uma organização produz efeitos profundos no comportamento dos seus membros relacionados à exigência de coordenação e controle dado o aumento da complexidade (Hall, 1982).

A diferenciação horizontal diz respeito à subdivisão das tarefas desempenhadas pela organização entre seus membros (Hall, 1982) e é medida pelo número de diferentes unidades dentro de uma organização (Hatch, 1997), que podem ser exemplificadas como partes responsáveis pela distribuição, vendas, marketing, contabilidade entre outras.

A diferenciação vertical, por sua vez, é uma questão menos complexa do que a diferenciação horizontal (Hall. 1982). Ela está relacionada diretamente com a proliferação dos níveis de supervisão (Meyer 1968). É a contagem do número de posições entre o executivo principal e os empregados que trabalham na produção (Pugh, Hickson, Hinnings e Turner 1968, apud Hall, 1982). Esse tipo de diferenciação está vinculado ao nível de autoridade e ambos os tipos de diferenciação apresentam problemas de controle, comunicação e coordenação às organizações (Hall 1982).

Finalmente, o elemento da complexidade pode ser uma forma de diferenciação vertical ou horizontal, isso porque as atividades e o pessoal podem dispersar-se no espaço (Hall 1982). 
A formalização representa o uso de normas numa organização (Hage e Aiken 1967, apud Hall, 1982). Organizações não-formalizadas são as que lidam constantemente com situações novas para as quais não existem precedentes (Hall, Estrutura e Processos, 1982, pg. 97). Dessa forma, podemos fazer uma análise da formalização através da proporção de tarefas codificadas e pela faixa de variação que é tolerada dentro das regras que definem as tarefas. Quanto mais alta a proporção de tarefas codificadas e menores as faixas de tolerância permitida, mais formalizada é a organização (Hage 1965). As condições de alta formalização indicam níveis de impessoalidade dentro da organização, pois reduzem o poder humano sobre suas ações e aumentam o controle através de normas e regras (Hatch, 1997)

A especificação de regras, procedimentos, penalidades e assim por diante predetermina boa parte do que ocorre numa organização. Com efeito, a formalização é uma característica fundamental das organizações, uma vez que o comportamento não ocorre ao acaso e se dirige à meta através de algum grau de formalização. (Hall, 1982, pg 74)

O último conceito apropriado das características estruturais de Hall é o de Centralização e ele se refere à distribuição de poder nas organizações. Em organizações centralizadas, as escolhas finais são feitas quase que exclusivamente nos altos níveis e não se espera que haja reflexão sobre a aceitação dessa decisão pelos níveis hierárquicos inferiores (Hatch, 1997, pg. 168). Organizações descentralizadas são aquelas que permitem a tomada de decisões por aqueles mais próximos à situação. A alta centralização demonstra uma falta de confiança no pessoal para que tomem decisões, ou se auto avaliem. O contrário indica uma maior autonomia dos membros para que eles desempenhem suas atividades de maneira mais autônoma (Hall, 1982). Por isso que estruturas burocráticas tendem a ser descentralizadas, pois confiam na formalização das ações, dinamizando o procedimento de fazer escolhas a partir de uma cultura organizacional instituída em todos os membros (Hatch, 1997).

Os estudos de Mintzberg (1994) sobre estruturas consolidam os parâmetros estruturais analisados na pesquisa e nos ditam características que se encaixam de forma fluida, ajudando a caracterizar as produtoras. As cinco configurações de Mintzberg são: Estrutura Simples, Burocracia Mecanizada, Burocracia Profissional, Forma Divisionalizada e Adhocracia.

A Burocracia Mecanizada é a que menos apresenta características reconhecidas nas organizações de produção criativa, pois é um tipo de estrutura que trata as pessoas como "meios", como "classes de posições e funções em lugar da individualidade" (Mintzberg, 1995, 
p. 201). Essa prática é inviável dentro de uma produção altamente capacitada através das habilidades e dos talentos de seus agentes. A Forma Divisionalizada tem como mecanismo de coordenação a padronização de resultados, fazendo com que também se distancie dos tipos estruturais das empresas de cinema brasileiras, que não formam uma tendência industrial propriamente dita. É difícil, também, controlar resultados de processos criativos como o da filmagem e da montagem por exemplo.

A Adhocracia tem seu mecanismo de coordenação baseado no ajustamento mútuo, que nos aproxima de empresas que pouco reverenciam os princípios clássicos da administração, especialmente para com a unidade de comando (Mintzberg, 1995):

Uma estrutura com pouca formalização de comportamento, grande especialização horizontal do trabalho baseada no treinamento formal; tendência para agrupar os especialistas em unidades funcionais com finalidades de administração interna, mas desdobrando-se em pequenas equipes de projeto baseadas no mercado para levar a efeito seu trabalho. Inovar significa rebelar-se contra padrões estabelecidos. (Mintzberg, 1995, pg 251)

É característica do ajustamento mútuo uma forma coletiva e dialogada para se resolverem os problemas de produção, sem que haja padronizações e formalização dos procedimentos. Por isso é a Adhocracia que sofre as dificuldades mais sérias quando sucumbe às pressões para burocratizar (Mintzberg, 1995).

A Burocracia Profissional prioriza a padronização de habilidades, configurando os profissionais dentro de um determinado espaço e tempo de atuação. São estruturas baseadas fortemente no treinamento formal, que no caso se refere ao conhecimento técnico e produção cinematográfica obtido em cursos, faculdades ou derivados. Esses especialistas acabam ganhando uma determinada parcela sobre o controle de seus trabalhos, mas ainda estão incumbidos a aceitarem modelos de coordenação baseadas na formalização e centralização da empresa.

Por último temos a Estrutura Simples, uma configuração cujas características se encontram em todas as produtoras estudadas mesmo que em níveis diferentes. É analisada por Mintzberg (1995) a grande vantagem da estrutura simples enquanto uma organização confortável para se trabalhar pelo seu tamanho e seu caráter pessoal, em que o líder sabe o que está fazendo. Porém, é nessa pessoalidade que ocorre um dos riscos da configuração simples: a dependência de que as metas sejam levadas pela figura de uma pessoa e não por processos de formalização, condiciona o modelo aos problemas pessoais de um indivíduo.

REAd | Porto Alegre - Edição 86 - No 2 - Maio / Agosto 2017 - p. 167 - 190 
Tipicamente, a organização que a utiliza tem pequena ou nenhuma estrutura, poucos assessores de apoio, divisão de trabalho não rigorosa, diferenciação mínima entre suas unidades e pequena hierarquia gerencial. Pouco do seu comportamento é formalizado e faz uso mínimo de planejamento, treinamento e de instrumentos de religação. Acima de tudo, é orgânica. (Mintzberg, 2012, pg 178, 179)

Cabe salientar, no entanto, que embora ilustrado teoricamente para análise de estrutura das produtoras, o trabalho de Mintzberg tem foco nos mecanismos internos de coordenação. No caso das produtoras, e talvez crescentemente de outros tipos de organizações do setor cultural, é ancorada a realização de suas atividades em mecanismos externos de coordenação, pautados na cooperação - redes e alianças, formais e informais. Também escapa à proposição de Hall, como de Mintzberg, o papel da confiança como mecanismo de coordenação das relações entre os diferentes atores em diferentes setores da economia criativa ou do setor cultural de forma geral. A difícil comparabilidade da "mercadoria" cinema, fez com que a economia deixasse de tratá-la como objeto importante de estudo para economistas clássicos, ganhando atenção somente na década de 60 a partir do trabalho de Baumol e Bowen (1969).

\section{Procedimentos metodológicos}

Este artigo é o resultado de um estudo exploratório, de natureza qualitativa (Silverman, 2009), que tem como unidade de análise produtoras de cinema. A opção por uma perspectiva exploratória e qualitativa pautou-se pela natureza do objeto e pelas questões que se procurou observar, ou seja, entender as formas como as empresas produtoras de cinema do Rio Grande do Sul se estruturam, e as principais diferenças que há entre elas, procurando uma ligação com o tipo de cinema produzido. A definição do tipo de cinema e da dinâmica de estruturação das atividades, considerando as peculiaridades das organizaçãos da indústria criativa, demandou a necessidade de uma interlocução direta com responsáveis tanto pela gestão quanto pela produção cinematográfica. Nesse sentido, entrevistas em profundidade se mostraram mais adequadas para captar as dimensões não expressas formalmente em documentos e pouco acessíveis através de instrumentos estruturados, tais como questionários.

Para a coleta de dados, foi necessário pensar um instrumento que pudesse ser aplicado em todas as produtoras. A partir disso, percebendo a importância de um diálogo entre o grupo de pesquisa e os profissionais, entrevistas, baseadas num roteiro, serviram para a coleta dos

REAd | Porto Alegre - Edição 86 - No 2 - Maio / Agosto 2017 - p. 167 - 190 
dados e uma aproximação maior da opinião crítica dos entrevistados. Para que a pesquisa contemplasse produtoras com diferentes estruturas, foi preciso um mapeamento prévio das mais diversas produtoras de cinema do Rio Grande do Sul que ainda estão em atuação e tenham produzido no mínimo um longa metragem desde 1995. A definição de metragem e data é importante para que a pesquisa possa ser enquadrada dentro de uma análise cinematográfica posterior ao período da retomada, momento em que, após o governo Collor, criou-se novas políticas de investimento público, aumentando o fomento pela produção cinematográfica do país.

A pesquisa foi realizada com as produtoras Avante Filmes, Gus Gus Cinema, Millimetros, Otto Desenhos, Prana Filmes, Panda Filmes, TGD Filmes e Tokyo Filmes. Com exceção da Millimetros, de Santa Maria, todas as empresas estão situadas em Porto Alegre. A produtora Otto Desenhos é a única que ocupa seu trabalho exclusivamente para animações. Os proprietários da Prana Filmes, fundada em 2012, são Carlos Gerbase e Luciana Tomasi, ex-sócios proprietários da Casa de Cinema de Porto Alegre. Essas produtoras, embora não componham a totalidade de empresas do ramo, funcionam como uma amostra significativa da população total, pois detém uma produção expressiva no total de filmes produzidos no Rio Grande do Sul.

A entrevista objetivou conhecer as organizações através de uma análise qualitativa de suas estruturas e formas de produção. As conversas foram gravadas, transcritas e finalmente analisadas levando em consideração as teorias discutidas na sessão de revisão teórica.

Abaixo a lista de produtoras, sua abreviação de identificação dentro da pesquisa e a função do entrevistado dentro da organização:

1) Avante Filmes (E1): sócio proprietário, diretor dos filmes da produtora;

2) Gus Gus Cinema (E2): sócio proprietário, diretor dos filmes da produtora;

3) Millimetros (E3): sócio proprietário;

4) Otto Desenhos (E4): gerente de projetos;

5) Tokyo Filmes (E5): sócio proprietário, diretor dos filmes da produtora;

6) Panda Filmes (E6): sócio proprietário, produtor executivo dos filmes da produtora;

7) Prana Filmes (E7): sócio proprietário, diretor dos filmes da produtora;

8) TGD (E8): coordenador do núcleo de produção de conteúdo.

REAd | Porto Alegre - Edição 86 - No 2 - Maio / Agosto 2017 - p. 167 - 190 
Embora a pesquisa não aborde todas as empresas produtoras do mercado, as que foram entrevistadas representam uma população heterogênea cujas características de estrutura e dos filmes que produzem diferenciam-se entre si, mas, dentro dos nichos que se situam, trazem qualidades que permitem serem utilizadas como modelos em comparação com as que não foram incluídas nesse trabalho.

\section{Resultados}

3.1 A indústria cinematográfica no Rio Grande do Sul

Em termos de estrutura organizativa ou de governança do setor de audivisual, o Rio Grande do Sul conta hoje, além das associações e secretarias de estado e município, com um APL (Arranjo Produtivo Local) formado por mais de 50 empresas e instituições gaúchas (empresas produtoras, distribuidoras, exibidoras, locadoras de equipamento, programadoras, estúdios de áudio e finalização, instituições de ensino, sindicatos e associações de grande participação e impacto no mercado audiovisual). Este APL teve sua criação proposta pela FUNDACINE (entidade gestora do APL do audiovisual), a qual contou com a colaboração da SIAV-RS e da APTC-ABD/RS.

O APL do audiovisual está baseado no princípio de estimular o uso de ferramentas de integração entre os principais agentes de um determinado setor industrial/comercial para alavancar e fortalecer mercados ou mesmo novos setores em processo de inserção no cenário econômico de uma determinada região. A criação do APL deu-se no âmbito da criação da política de desenvolvimento industrial do Rio Grande do Sul, em 2012, onde o setor da economia criativa foi incluído nessa nova política, e o setor de audivisual foi definido como estratégico para o desenvolvimento.

Este APL busca a integração dos agentes locais de forma a aperfeiçoar a coordenação das ações de desenvolvimento do setor, a oferta de serviços às empresas e projetos cooperados. Acredita-se que dessa forma será possível alcançar maior eficiência econômica coletiva e assim ampliar a geração de trabalho, maior valor agregado e aumento de renda. Destaca-se no documento da criação do APL o foco no fortalecimento da área de comercialização/distribuição de obras audivisuais. Para Barone (2013) está é uma das áreas que mais necessitam de atenção, salientando a necessidade de iniciativa para melhorar as condições de circulação dos produtos audivisuais gaúchos em diferentes mercados. 
Barone (2013) também destaca como foco do APL, sob coordenação da FUNDACINE, responder pelo estabelecimento de uma governança capaz de organizar as iniciativas para ações colaborativas entre as empresas e as instituições.

A produção cinematográfica do Rio Grande do Sul, assim como toda produção nacional, passou por radicais mudanças ao longo do período iniciado a partir da retomada. Nesse contexto, órgãos regulamentadores, em âmbito nacional e regional, se tornaram essenciais para gerenciar a relação entre os produtores audiovisuais e os mecanismos de fomento. No Rio Grande do Sul, a Associação Profissional de Técnicos Cinematográficos, APTC, foi criada em 1985, sendo então anterior a Ancine, e consolida-se no estado como a mais forte associação de profissionais do ramo. Seus objetivos principais são o da democratização, implantação de processos transparentes, valorização do trabalhador, acentuação dos processos associativos e criativos, colaborativos e coletivos, exercitar a cidadania e, claro, fazer cinema (Scomazzon, 2011). A APTC participa da regulamentação e fiscalização de inúmeros editais, tais como o de curtas da RBS, do desenvolvimento de projetos da prefeitura de Porto Alegre com o Banco Santander, do Curta nas Telas juntamente com a prefeitura de Porto Alegre e com o sindicato dos exibidores. Atualmente, a APTC tenta conseguir apoio dos seus membros e profissionais da área cultural para discutir medidas do governo do estado que fechou temporariamente o sistema Pró-Cultura RS, diminuindo a participação das Leis de Incentivo à Cultura (LIC) no estado.

O Rio Grande do Sul também observou transformações estéticas e metodológicas de produção ao longo desse período. À época da criação da APTC, rodavam-se muitos filmes de baixo orçamento, realizados, na maioria, por estudantes de comunicação com bitola Super-8. Em 1981, Giba Assis Brasil e Nelson Nadotti realizaram o antológico Deu pra ti, anos 70, filme que configurou a estética e a produção cinematográfica da época através de parceiras entre produtores sem vínculos contratuais que estavam preocupados exclusivamente em fazer o filme. Deu para ti, anos 70 foi peça importante para o desenvolvimento de uma das produtoras mais influentes do cinema nacional, a Casa de Cinema de Porto Alegre, cujos sócios hoje são Giba Assis Brasil, Ana Luiza Azevedo, Jorge Furtado e Nora Goulart. Com a retomada, a criação da Ancine e o desenvolvimento de editais e leis de incentivo as produções ganharam tamanho em questões financeiras, houve a profissionalização da mão de obra e a criação de faculdades de cinema e televisão pelo estado. Assim, os modos de produção também mudaram. Fazer um filme estava fortemente ligado à captação de dinheiro através das leis de incentivo, como a Lei Rouanet, e editais de fomento. No Rio Grande do Sul, o REAd | Porto Alegre - Edição 86 - No 2 - Maio / Agosto 2017 - p. 167 - 190 
Fumproarte, através da Secretaria Municipal da Cultura, articula-se como um dos principais fundos de incentivo a diversas áreas da cultura.

No ano de 2014, o estado obteve uma seleção inédita para o Festival de Berlim, na mostra Berlinale, com o filme Castanha, de Davi Pretto (Tokyo Filmes). No ano seguinte, Beira-Mar, de Filipe Matzenbacher e Márcio Reolon (Avante Filmes), esteve presente na mesma mostra. Essa dupla consagração do cinema gaúcho mostra um desenvolvimento estético e uma nova forma de pensar os modos de produção. Quando entrevistados para essa pesquisa, os realizadores desses filmes se mostraram posicionados com um cinema que dialoga com questões de desenvolvimento estético, portanto surgem como peças artísticas. As relações de parceria, embora peculiares a cada filme, são semelhantes e se comparam com as formas de produção baseadas nos vínculos amistosos, sem contrato profissional, tais quais eram feito os filmes no início dos anos 1980. Pretto arrecadou dinheiro para a realização do filme através do edital do Fumproarte, já Matzenbacher e Reolon filmaram sem dinheiro público, recorrendo a editais apenas para finalização do filme.

Os dois filmes apostam em uma ideologia que está crescendo no cenário do cinema independente: para o filme ter sucesso no Brasil, será preciso, antes, ter sucesso em festivais internacionais. Assim a estreia desses filmes no Brasil e seus vínculos com distribuidoras estão fortemente ligadas com o sucesso internacional. O reconhecimento como importantes produções gaúchas, principalmente no quesito de desenvolvimento estético, acentuam as diferentes formas de produção de um filme baseados na antítese de fins mercadológicos e artísticos.

\subsection{Produtoras gaúchas e suas estruturas organizacionais}

Para diferenciar as produtoras dentro de uma análise estrutural foi preciso reconhecer os diferentes tamanhos de cada. Dois componentes do tamanho serão variantes no processo de análise: a capacidade física da organização e pessoal disponível (Hall, 1984). Partindo dessas duas determinações de tamanho já podemos distinguir as produtoras para depois refletirmos sobre a estrutura. A Tabela 1 mostra os dados coletados referentes a essas variantes.

\begin{tabular}{l|lc} 
Produtoras & Possuí sede física & Número de pessoal \\
\hline Otto Desenhos & Sim & 18
\end{tabular}

REAd | Porto Alegre - Edição 86 - Nº 2 - Maio / Agosto 2017 - p. 167 - 190 


\begin{tabular}{l|lc}
\hline Panda Filmes & Sim & 12 \\
\hline TGD & Sim & 12 \\
\hline Avante Filmes & Sim & 6 \\
\hline Tokyo Filmes & Não & 4 \\
\hline Prana FIlmes & Sim & 2 \\
\hline Gus Gus Cinema & Não & 1 \\
\hline Millimetros & Sim & 1 \\
\hline
\end{tabular}

Tabela 1 - Sede física e número de pessoal de cada produtora

As três maiores produtoras, ao nível de número de pessoal, são a Otto Desenhos, a Panda Filmes e a TGD. São elas também as que apresentam uma maior diferenciação vertical, confirmando a correlação entre tamanho e diferenciação vertical mais acentuada (Hall, Haas e Johnson, 1967). A diferença de tamanho também acarreta em outras diferenciações estruturais. Há na Otto Desenhos, na Panda Filmes e na TGD uma maior complexidade e maior centralização em comparação com produtoras independentes como a Avante Filmes, que apresenta um número de pessoal relativamente grande. A figura do Otto Guerra, proprietário da Otto Desenhos, reflete a imagem do proprietário clássico de uma organização capitalista, da qual uma pessoa coordena a produção e detém o conhecimento técnico. No caso de Otto Guerra é a sua criatividade artística e talento para o desenho gráfico que o coloca no centro de uma organização segmentada através da diferenciação horizontal e vertical, capaz de produzir o filme com um número amplo de funcionários cujas capacidades técnicas e produtivas os alocam em funções diferentes dentro da empresa.

A TGD reflete em sua estrutura a sua atuação no mercado: mais ampla que o restante das produtoras, pois possui subunidades para diferentes segmentos do audiovisual.

"Hoje se trabalha em todos os âmbitos do audiovisual, tem tanto a produção de curtas metragens, longas metragens, publicidades e o que hoje o mercado tá começando a chamar de conteúdo", E8. 
Há, na estrutura da TGD, núcleos e departamentos que indicam o seu tamanho e seu nível burocrático semelhante ao da Otto Desenhos e da Panda Filmes.

As produtoras Avante Filmes, Gus Gus Cinema, Tokyo Filmes e Millimetros são reconhecidas como as produtoras independentes de cinema. Suas estruturas fogem do usual e são formadas, em sua maioria, por jovens realizadores e graduados em faculdades de cinema. Essas produtoras possuem características estruturais, como de se esperar, menos complexas em relação às empresas maiores. $\mathrm{O}$ descompromisso com os conceitos de estrutura e uma falta de preocupação com a organização formal da empresa surge do fato de que as empresas foram criadas somente para responder às questões legais do mercado cinematográfico, como a participação de editais, festivais e captação de recursos, diferente das empresas citadas anteriormente cuja finalidade de existência está pautada visivelmente no mercado.

Baseada nessa análise, podemos separar as produtoras utilizando os conceitos de Mintzberg de Adhocracia e Burocracia Profissional, como mostra a Tabela 2.

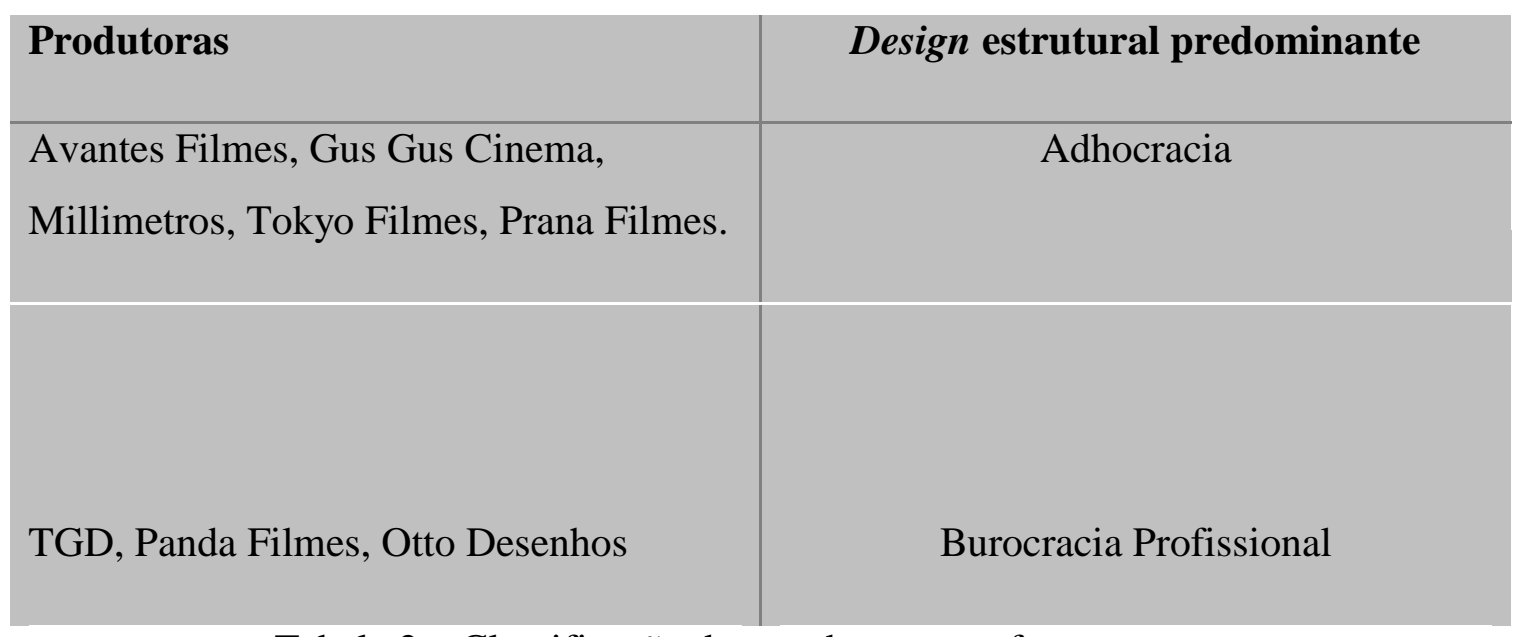

Tabela 2 - Classificação das produtoras conforme sua estrutura

É importante salientar que em geral burocracias profissionais apresentam maior grau de complexidade, como é o caso de hospitais e universidades, evidenciando claramente as diferentes partes. No entanto, a presença forte de um núcleo operacional profissionalizado, onde a coordenação ocorre a partir da padronização de habilidades permite aproximarmos as produtoras de uma burocracia profissional. Por outro lado, aquelas definidas como adhocráticas apresentam um corpo funcional com elevada qualificação técnica, mas o ajustamento mútuo e o trabalho em times por projetos às aproxima mais de uma adhocracia, conforme descrito por Mintzberg (1994). 
3.3 As produtoras e suas visões sobre cinema

Após classificadas as produtoras, pode-se correlacionar o design estrutural delas e suas visões sobre cinema buscando compreender os diferentes tipos de cinema produzidos no Rio Grande do Sul destacando os diferentes tipos de estrutura que formam a cadeia produtiva de cinema no estado.

A visão de cinema exclusivamente como arte apareceu somente a partir de três produtoras cujos designs estruturais encaixam-se com o tipo de Adhocracia: Avante Filmes, Gus Gus Cinema e Tokyo Filmes. Para entrevistado (E1) da Avante Filmes o cinema está relacionado com uma frase proferida pelo realizador alemão Wim Wenders, cuja função do cinema não é de entreter, mas sim de fazer sonhar, e conclui: "para mim é arte, há ali uma terapia”. A visão artística do cinema transcende e toca a proporção da força do autor, uma visão similar à política dos autores. Gustavo Spolidoro (E2) discorre sobre o assunto a partir da crença na força de expressão do cinema como visão de mundo de um único indivíduo, base para a criação do curso "Cinema de um Homem Só" que ministrou em 2014. Sua visão de arte vincula-se a questões existenciais do ser humano: "porque, no momento em que eu penso em arte, eu me sinto livre para criar. Se eu penso comercialmente eu não existiria”. Nestes dois casos, os entrevistados se mostraram cientes com a existência de uma visão oposta, de cinema de entretenimento e completaram que não veem problema na existência do mesmo. "A gente faz filmes sob encomenda, filmes que a gente é contratado para fazer, mas mesmo neles a gente sempre tem uma preocupação artística muito grande", diz E1.

A relação de um filme artístico com a inexistência de amarras burocráticas, dentro de uma empresa, é imprescindível para E2, que se vê capaz de fazer filmes baseados em sua visão somente através de sua empresa "de um homem só": "a minha postura faz com que eu não seja até bem visto por quem tem visão comercial" e conclui "arte é liberdade". Uma visão mais crítica e politizada pode ser percebida pelo entrevistado E3, da Millimteros, que vê o cinema com determinada obrigação de atingir metas comerciais, pelo menos o produzido através de recursos públicos. "Eu acho que a função primordial do cinema do nosso país é produzir reflexão. Ele também tem que chegar ao público, porque é recurso público. É banalidade da coisa ela funcionar exclusivamente nessa questão do entretenimento (...) o cinema pode ser só entretenimento, mas dificilmente será só arte, pois a arte é um tipo de entretenimento."

REAd | Porto Alegre - Edição 86 - No 2 - Maio / Agosto 2017 - p. 167 - 190 
A visão mais onírica sobre cinema e arte veio do E5, que diz produzir arte mesmo que isso signifique algo sem utilidade dentro de uma sociedade pragmática e capitalista. "A arte é como um E.T. que chega na terra, tu olha e pergunta o que ele está fazendo aqui”, diz E5. Juntamente com a empresa Prana Filmes, estas produtoras representam empresas que apresentaram uma estrutura adhocrática e vinculam suas existências a ultrapassar as barreiras burocráticas do processo de realização de cinema. A Avante e a Tokyo foram criadas para poderem ingressar em editais de recursos públicos e de festivais, enquanto a Gus Gus Cinema surgiu para um trabalho de rádio, em 1996, para que o proprietário pudesse emitir notas fiscais, a tarefa de produção audiovisual foi anexada no contrato social como secundária. Essa existência voltada para poder "jogar com as regras do jogo", ao invés de criar uma empresa competitiva dentro de um determinado mercado, é uma das diferenças que estas empresas têm em relação às empresas de Burocracia Profissional.

O cinema como entretenimento comercial surge como uma preocupação de algumas empresas a partir do momento em que suas configurações estruturais começam a se preocupar com algum tipo de padronização de resultados: desde questões estéticas a resultados de bilheteria. No caso das produtoras TGD, Panda e Otto Desenhos, a tenuidade entre a Burocracia Profissional (descentralização a partir do controle tomado pelo especialista) e a Forma Divisionalizada (determinação de resultados finais) revela a necessidade de indícios burocráticos para a realização do filme. Foram estas produtoras que incluíram em suas análises uma visão comercial significativa. Para E8, a discussão da arte e do comercial retoma ao período Renascentista: "aquela questão da arte pela arte é um pouco reducionista, pois a Capela Sistina e outras grandes obras foram feitas por encomenda e agora tu vai dizer que não é arte. Também é um objeto comercializado. Então essa questão da arte pela arte tem espaço, mas não queria ter aceitação comercial. Se tu queres fazer a arte pela arte então te desenvolva e desenvolva a tua linguagem, não espere algum retorno, até porque isso é um dos princípios da arte, o não retorno. Se tu ouvir as críticas, então se cale".

E8 completa que há um controle da produção oriunda de outras fontes que não a empresa, como, por exemplo, das distribuidoras, que cada vez mais tem poder de decisão no filme, e das políticas públicas que, com a forte presença do Fundo Setorial Audiovisual (FSA), influenciaram a produção de filmes de comédia:

"se a gente fez um filme que teve uma boa bilheteria, nós vamos ter possibilidade de conseguir mais recurso para um segundo filme. Mas hoje, no Brasil, pra ter boa bilheteria significa tu fazer comédia. Então REAd | Porto Alegre - Edição 86 - Nº 2 - Maio / Agosto 2017 - p. 167 - 190 
se tu não fez uma comédia, teu trabalho vai ser muito mais árduo e talvez tu não consiga fazer um segundo, terceiro filme, com tanta facilidade".(E8)

Obviamente a visão de um cinema artístico não é negada por nenhuma produtora. Nem mesmo pelas empresas que se estruturam a partir da Burocracia Profissional, cujas amarras normativas tiram um pouco do caráter imaterial e pessoal do trabalho. O que muda é apenas uma visão geral, não só uma preocupação com o produto (filme), mas também com o mercado (cinema). Essa relevância cria limitações na produção, determina prazos, gera contratos, que constrangem a liberdade artística proferida por empresas de estrutura adhocrática. Para E6, da Panda Filmes, a configuração de arte ou entretenimento se encaixa numa determinação psicanalítica, individual:

"Eu fiquei pensando assim: dentro daquele principio da psicanálise de tu te colocar na pele do outro, não julgar com teu olhar. As pessoas indo no cinema ver aquele filme (Bilbao, de Bigas Luna, 1978), dada a bizarrice e quão ele é trash, umas coisas toscas na montagem, nos enquadramentos, mas tudo tem arte e entretenimento". (E6)

\section{CONSIDERAÇÕES FINAIS}

Neste estudo encontramos uma forte relação entre a estrutura de uma empresa e sua visão sobre cinema. As empresas Avantes Filmes, Gus Gus Cinema, Millimetros, Tokyo Filmes, Prana Filmes, que apresentam uma estrutura adhocrática, incluem uma visão aguda sobre a relação íntima entre cinema e arte. Para esses produtores, as relações de uma empresa gerida por questões clássicas da administração não surgem como principal foco de discussão. Priorizam, antes de se manterem vivas no mercado, a realização de seus filmes, marcados por traços autorais e de experimentação de linguagem, e nem por isso ignoram ou veem com maus olhos uma produção voltada para o mercado, para o entretenimento. O cinema de arte traz o filme como o fim; a produtora, o meio. TGD Filmes, Panda Filmes e Otto Desenhos condizem mais com empresas em nível maior de formalização, centralização e normatização. São empresas de Burocracia Profissional, que tentam manter um determinado controle sobre o resultado final de seus produtos para que possam deter maior poder de decisão e de atuação no mercado audiovisual.

Não é incomum encontrarmos essas produtoras variando o seu tipo de estrutura. É difícil dentro do mercado criativo e artístico, tão livre de amarras técnicas e materiais, definirmos com precisão as características gerais das empresas. O cinema, sendo uma forma REAd | Porto Alegre - Edição 86 - Nº 2 - Maio / Agosto 2017 - p. 167 - 190 
de produção que gera altos custos e números não pequenos de pessoas envolvidas, necessita uma mínima ordem de conduta que orienta as produtoras a flexionarem-se entre as duas formas de estrutura. Até mesmo as empresas desburocratizadas perdem um pouco da sua leveza gerencial, quanto as empresas mais formalizadas acabam cedendo espaço para um habitual diálogo mais informal entre os envolvidos na produção. Podemos dizer que há uma convergência, em alguns momentos, entre as produtoras adhocráticas e as de Burocracia Profissional.

É equivocado negar o caráter artístico de qualquer filme produzido por qualquer produtora. Mesmo as que preferem ver seu cinema mais voltado para as salas de cinema comercial, elas almejam uma discussão artística de seus trabalhos. Isso, pois todo cinema é uma peça estética, elemento básico da configuração de arte. Em nenhum momento foi negada a visão de arte por qualquer empresa, rejeitando a existência e o valor artístico. As empresas de Burocracia Profissional apenas preferem não priorizar o rótulo de arte.

Então há motivos para abrir espaço para esse tipo de discussão?

Buscando entender e reconhecer as estruturas organizacionais das produtoras gaúchas, ajudamos a conceber maneiras de fomentar, apoiar e incentivar a realização de cinema a partir de incentivos justos, disponibilizados de forma coerente entre as produtoras que as eles recorrem. Conforme a Superintendência de Acompanhamento de Mercado da ANCINE, percebemos o crescimento da produção cinematográfica nacional, que em 2013 chegou a cerca de 127 filmes lançados, resultado de uma evolução anual das perspectivas positivas que o mercado audiovisual vem gerando. Em 1995, ano em que se deu a retomada do cinema brasileiro, apenas 14 filmes nacionais foram lançados, 89\% menos que em 2013.

Esse crescimento engloba tanto os filmes comerciais quanto os artísticos, pois um é consequência do outro, já que a ascensão do mercado incentiva a formação de público e a formação de profissionais. Assim é de interesse dos órgãos de fomento uma análise particular da divisão artística e comercial do cinema para que não haja anulação de um dos segmentos. O interesse em ver os filmes de cunho artístico refletindo na ascensão do mercado é percebido na nova política do FSA que criou uma nova linha de investimento no PRODECINE: Projetos de produção de longa-metragens com propostas de linguagem inovadora e relevância artística, cujos benefícios se estendem aos projetos “com propostas de linguagem inovadora e relevância artística, com potencial de participação e premiação em festivais, que apontem para a experimentação e a pesquisa de linguagem, que sejam capazes de dialogar com seu públicoalvo e de realizar seu potencial comercial na fatia de mercado específica que almejam”. Logo, 
o FSA assume a existência de mercados que variam a partir da análise de cinema que o autor escolhe, protegendo os cineastas que produzem a partir dessa linha de concorrerem em um ambiente de produção industrial, modelo de negócio dominante no mercado audiovisual, que leva a uma menor diversidade de conteúdo, menor variabilidade de linguagens e menos interatividade, uma vez que o compromisso primeiro com a rentabilidade diminui a inovação artística (Cesário, 2007).

Dessa forma, recria-se a relação do profissional empresarial vinculado a produção cinematográfica, pois muitos realizadores se veem na condição de administradores de empresas, algo que pode nunca ter ocorrido como ideia de profissão. O processo de tomada de decisões, as hierarquias, o repasse de informação, as subunidades, são algumas variáveis dentro das diversas produtoras que ajudam a construir uma rede de empresas heterogêneas cujas características ímpares desenvolvem o audiovisual do país.

É necessária uma discussão acerca do assunto. Mostrar que rotular o cinema ainda é atual mesmo que se limite no discurso acadêmico. Esse embate, mesmo que às vezes traga um mal estar aos produtores, é na verdade feito para eles e para que eles possam se beneficiar de legislações que se apoiam nessa diferença. A tarefa acadêmica não é segregar, não é preferir, não é inibir. Nossa tarefa é criar uma lente para que possamos ver o mundo diferente, buscando uma compreensão melhor deste. Tarefa que os cineastas executam com precisão.

Finalmente, para fechar a conclusão, sugerimmos que sejam realizados estudos que procurem explorar as transformações do cinema nacional a partir das mudanças na governança do setor, como a criação de APLs, dentre outras medidas. Ao longo da pesquisa, embora os mecanismos externos de coordenação não fossem objeto de análise, não ocorreram manifestações dos entrevistados e não se verificou nos dados secundários, referências quanto ao impacto da criação do APL do audivisual na capacidade de produção, distribuição e exibição da produção gaúcha. Isso, talvez, possa ser explicado pela natureza recente da criação do projeto, além do fato de que não era objeto da pesquisa a compreensão de mecanismos externos de governança.

\section{REFERÊNCIAS}

ANCINE. Informe de Acompanhamento do Mercado - Salas de exibição. Informe anual preliminar 2013 - semanas 1 a 52 de 2013. Publicado no Observatório Brasileiro do Cinema e do Audiovisual - OCA em 15/01/2014.

AUMONT, J. et al. A estética do filme. 9. ed. Campinas, Sp: Papirus, 2011.

REAd | Porto Alegre - Edição 86 - No 2 - Maio / Agosto 2017 - p. 167 - 190 
BAUMOL, W.; BOWEN, W. Performin arts: the economic dilema. Massachussets: Yale University Press, 1969.

BERNADET, J. C. O que é cinema? Brasiliense, 1980.

BRANDÃO, H. S. M. “A fábrica de imagens” $O$ cinema como arte plástica e rítmica. Universidade de Lisboa, Faculdade de Letras, Departamento de Filosofia, 2008.

CESÁRIO, L. B. Reflexões sobre as atuais políticas públicas para o cinema no Brasil em meio à transnacionalização da cultura. Revista da FAMECOS/PUCRS, Porto Alegre, n. 18, 2007.

HATCH, M. J. Organization theory. Nova York, Oxford University Press, 1997.

DAHL, G. Arte ou Indústria. 2002. Disponível em:

<http://www.ancine.gov.br/sites/default/files/artigos/arte_ou_industria.pdf> Acesso em: 16 maio 2014.

HALL, R. H. Organizações: estrutura e processos. 3. ed. Rio de Janeiro: Prentice - Hall do Brasil, 1984.

MINTZBERG, H. Criando organizações eficazes - estruturas em cinco configurações. 2. ed. São Paulo. Atlas, 1995.

RANSON, S.; HININGS, B.; GREENWOOD, R. The structuring of organizational structures. Administrative Science Quarterly, Thousand Oaks, v. 25 n. 1, p. 1-17, mar. 1980.

ROCHA, G. Eztetyka da Fome. In: Revolução do cinema novo. São Paulo. Cosac \& Naif, 2004.

SILVERMAN, D. Interpretação de dados qualitativos: métodos para análise de entrevistas, textos e interações. Ed. Bookman, Porto Alegre, 2009.

SCOMAZZON, C. APTC, 25 anos - Eles só queriam fazer seu próximo filme. Casa Verde, Porto Alegre 2011.

XAVIER, I. Discurso cinematográfico - a opacidade e a transparência. 4. Ed. São Paulo. Paz e Terra, 2008. 